\title{
Endurance exercise: a model of physiological integration
}

\author{
Francisco Javier Calderón-Montero', Juan José Ramos-Álvarez², Irma Lorenzo Capella³
}

'Department of Human performance and Health. Faculty of Physical Activity and Sport Sciences. INEF. Madrid Polytechnic University. Madrid. Spain. ${ }^{2}$ School of sports medicine. Faculty of Medicine. Complutense University. Madrid. Spain. ${ }^{3}$ Faculty of Education and Health. Camilo José Cela University. Madrid. Spain.

doi: 10.18176/archmeddeporte.00062

Received: 08/10/2020

Accepted: $22 / 04 / 2021$

Key words:

Endurance. Exercise. Feedforward. Feedback. Integration.

\section{Summary}

Endurance exercise is a model of physiological integration. There is no other animal activity in which cardiovascular, respiratory, metabolic-endocrine and neuromuscular functions are activated at the same time. Even apparently, silent functions are essential during exercise (digestive, renal). During long-term exercise, the absorption of water and carbohydrates is a determining factor in performance. Kidney function plays a fundamental role in trying to preserve the hydro-electrolyte balance during exercise. In this work we present an integrative physiological perspective during dynamic exercise (mobilization of a large muscle mass with a low to moderate degree of strength development), both from the point of view of health and performance. The response of the heart rate in the first moments of exercise is a good example of the feedforward mechanism. Overall, the nervous system has two control mechanisms: feedforward and feedback. These depend on the central command, a more functional than anatomical entity. The feedforward system allows to immediately start the cardiovascular and respiratory systems. This mechanism is important because it activates the organism to overcome resting state. The feedback system is equally important because it allows the central command to receive the necessary information to "order" the appropriate response according to the intensity of the exercise. The information for retrocontrol comes from various receptors located in: the muscles, the respiratory system and the cardiovascular system. It is complex information that the central nervous system processes with exquisite precision, as can be seen in in endurance exercise.

\section{El ejercicio de resistencia: un modelo de integración fisiológica}

\section{Resumen}

El ejercicio dinámico constituye el paradigma de la integración fisiológica. No hay ninguna otra actividad animal en la que se pongan en marcha al mismo tiempo las funciones cardiovasculares, respiratoria, metabolo-endocrina y neuromuscular. Incluso funciones, aparentemente silentes, son esenciales durante el ejercicio (digestiva, renal). Durante ejercicios de larga duración la absorción de agua y carbohidratos es determinante de rendimiento. Así mismo, la función renal juega un pape fundamental en intentar preservar el equilibrio hidro-electrolítico durante el ejercicio. En este trabajo presentamos una perspectiva fisiológica integradora durante el ejercicio dinámico (movilización de una gran masa muscular con bajo a moderado grado de desarrollo de fuerza), tanto desde el punto de vista de la salud como del rendimiento. De forma global y simplificada el sistema nervioso dispone de dos mecanismos de control: el feedforward y el feedback, dependientes de una entidad más funcional que anatómica, el comando central. El sistema feedforward permite poner en marcha de forma inmediata fundamentalmente al sistema cardiovascular y respiratorio. La respuesta de la frecuencia cardiaca en los primeros instantes de ejercicio es un buen ejemplo de la puesta en marcha del mecanismo de feedforward. Este mecanismo es transcendental para poner en funcionamiento al organismo a partir de un estado de reposo. El sistema feedback es igualmente importante pues

Palabras clave:

Resistencia. Ejercicio.

Retroalimentación. Control neuronal. Integración. permite al comando central recibir la múltiple información necesaria para "ordenar"la respuesta adecuada a la intensidad del ejercicio. La información para el retrocontrol parte de diversos receptores localizados en: la musculatura, el aparato respiratorio y el sistema cardiovascular. Realmente, es una información compleja que el sistema nervioso central procesa con exquisita precisión, como se puede poner de manifiesto en el ejercicio de resistencia. 


\section{Introduction}

Aerobic exercise is the preferred option to maintain or improve physical fitness in the western world according to the number of practitioners. In the US alone the number of practitioners of sports considered as dynamic by the Mitchell classification', sports in which endurance is considered the determinant capacity involved, was estimated at over 66.2 million in 2017. Even if this calculation has considered as practitioners those who use any modality of endurance exercise for fitness, therefore including jogging, running, cycling, and even walking, considered as sport, this high number suggests the importance of endurance and its training for both public health and sports.

From the perspective of Physiology as a science, endurance exercise is a learning opportunity. As a situation where the sheer stress created by the effort virtually compromises most physiological functions in the body, it has become the paradigm to describe the integration of every physiological system in an attempt to cope with increasing demands. The cardiovascular, metabolic and neuroendocrine adjustments must be precise in their tuning to fit the needs of different exercises. It is generally understood that even Nordic walking would already show this physiological integration².

At the same time, it may be easily overlooked that the so-called "silent" physiological functions, such as the renal or digestive systems, may also be compromised during very long efforts. In types of exercises considered extreme, such as an ultra-endurance event, the need to restitute substrates ${ }^{3-5}$, together with the need to maintain hydroelectric homeostasis ${ }^{6,7}$, make the digestive function of capital importance in this context. The absorption and delivery of nutrients has to be assured although blood flow to those organs will be extremely reduced ${ }^{8}$. Also filtering the blood becomes fundamental in endurance events 9 . Even though the blood flow to the kidneys will be minimal, these organs must perform at a high rate in order to ensure that a large proportion of cardiac output is destined to the exercising muscle ${ }^{10}$.

From the perspective of an integrated response, we may see the central nervous system as the main element responsible for the coordination of such a complex response involving all the adjustments required by a moving human body during endurance exercise. Although it is only real if used as a simple level of analysis, Figure 1 illustrates its importance. This simplified model suggests:

The Somatic Nervous System (SNS) must activate the necessary motor units, in the proper order, depending on the intensity of the effort. It does so as follows: activation will descend through the motor pathways ${ }^{11}$ and will synapse to motor neurons responsible for the activation of the chosen motor units of the necessary muscles.

The Vegetative Nervous System (VSN) must not only activate the neurons located in the intermediate horn of the spinal cord to activate the thoracic-lumbar system (sympathetic system) ${ }^{12}$ but also, at the same time, modulate the activity of neurons located in different encephalic structures in order to attenuate the activity of the cranial-caudal system

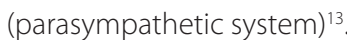

The aim of this paper is to summarize and review, from an academic perspective, existing knowledge on the physiological integration of all organs and tissues produced during the most natural stress suffered by an animal, exercise. We will mainly use other reviews and specific textbooks on the topic of sport physiology.

Figure 1. Schematic representation of the integrated response of the body to exercise. The nervous system adjusts the oxygen supply system and metabolism while it selects motor units depending on the intensity of the contraction. As with any other regulation mechanism it requires feedback control suggested here by a discontinuous line.

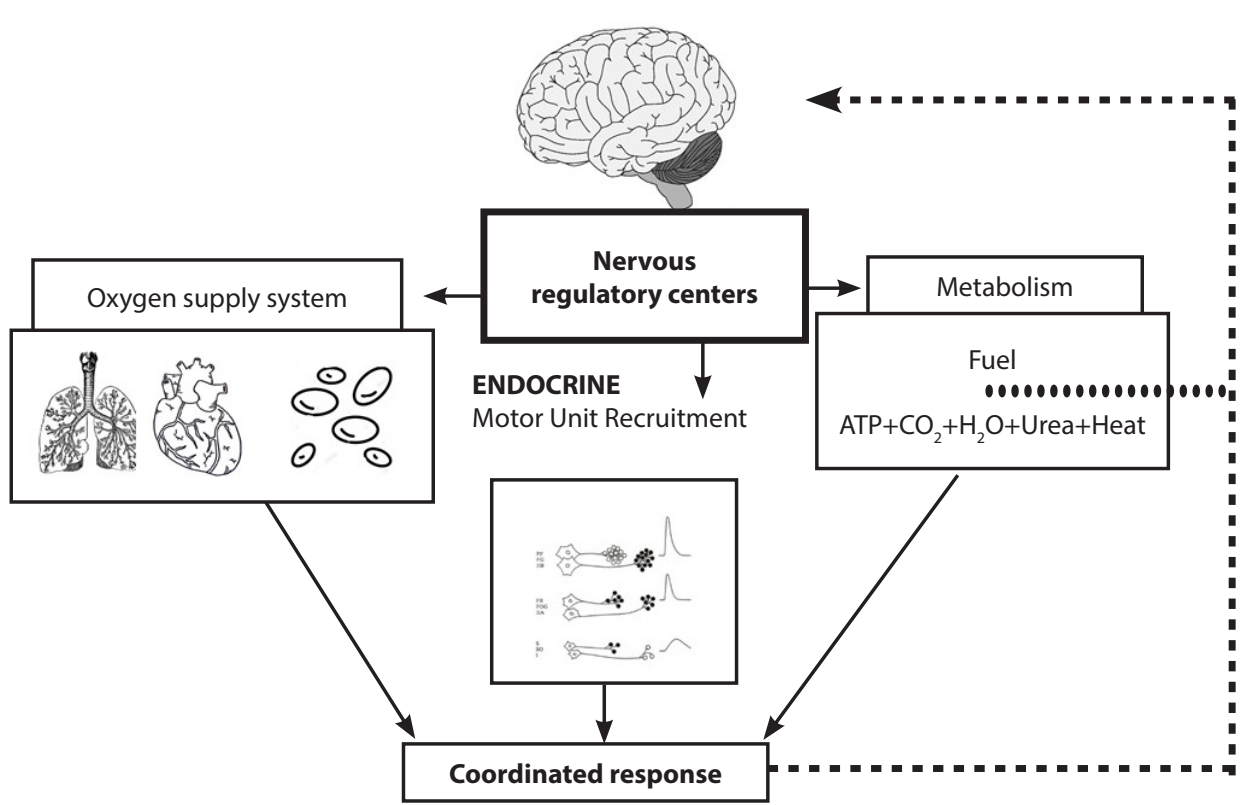




\section{Physiological parameters resulting from integration during endurance exercise}

The integrated response to endurance exercise can be determined through a number of physiological parameters as a result of the coordination of every compromised organ and tissue.

Oxygen consumption $\left(\dot{\mathrm{V}}_{2}\right)$ is the parameter that integrates the respiratory, cardiovascular, endocrine and metabolic functions. The higher use of oxygen mostly by muscular tissue is necessary in order to obtain energy. It is also fundamental to increase the availability of different energy substrates. Although metabolism has many and very powerful enzymatic control mechanisms, they are not fast enough to provide the necessary energy ratio. Endocrine control acts precisely on key enzymes to achieve and maintain the use of substrates. At the same time, temperature is another main variable to be controlled during endurance exercise.

\section{Oxygen consumption ( $\left.\mathrm{V}_{2}\right)$ during endurance exercise}

Figure 2 shows stability of oxygen consumption during an exercise test in our laboratory.

To understand the importance of this integrative parameter we can use the following analysis: An elemental understanding of $\dot{V}_{2}$ through gas analysis leads to the following equation:

$$
\begin{gathered}
\dot{V} O_{2}=\left(\dot{V} \cdot F_{1} O_{2}\right)-\left(\dot{V}_{E} \cdot F_{E} O_{2}\right) \text {; if } \dot{V}=\dot{V} \text {, then } \\
\dot{V} O_{2}=\dot{V}_{E}\left(F_{1} O_{2}-F_{E} O_{2}\right) \text { (equation 1) }
\end{gathered}
$$

But this equation is only valid whenever the respiratory quotient is below one $\left(\dot{V}_{1}=\dot{V}_{p}\right)$.

To assess $\dot{V}_{2}$ over unity it is necessary to use the Geppert and Zunt transformation ${ }^{14}$ usually attributed to Haldane.

On the other hand, if in the Fick equation for cardiac output determination $\dot{V}_{2}$ is expressed as a variable dependent on $\dot{Q}$ and the arterial-venous oxygen difference, we obtain equation 2.

$$
\dot{Q}=\left(\dot{V} O_{2}\right) /\left(\text { Dif } a-v O_{2}\right) ; \dot{V} O_{2}=\dot{Q} \cdot \operatorname{Dif} a-v O_{2}(\text { equation } 2)
$$

Figure 2. Oxygen consumption during a 30' constant intensity exercise on a cycle ergometer.

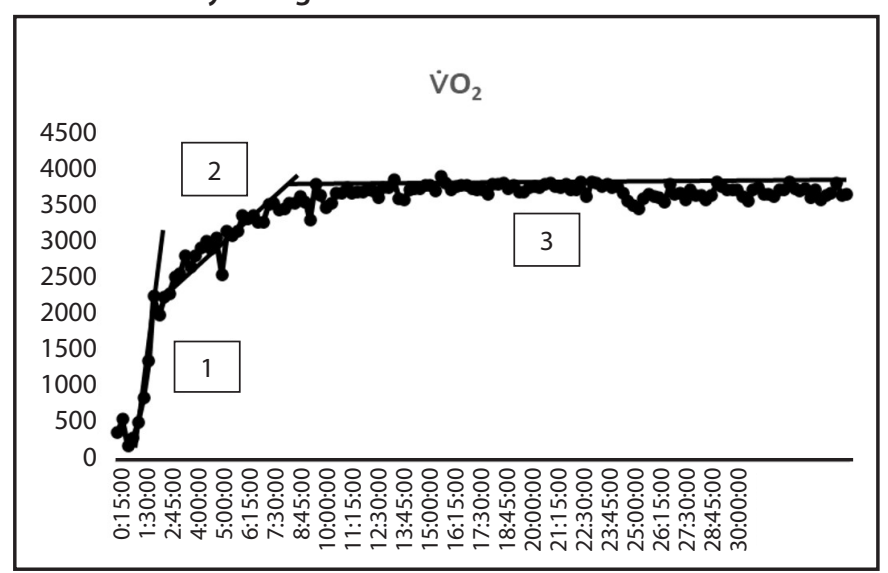

Printed with permission of the Sport Science Faculty of the Madrid Polytechnic University.
Using equation 1 and 2 we can obtain a good conceptual idea of oxygen consumption as shown in Figure 3. The consumption of oxygen is determined by respiratory, cardiac and cellular functions. All of them, on the one hand, are giving the necessary push to make oxygen available and on the other hand, are consuming it to continue functioning. Excellent coordination of all these systems is necessary for a good performance in an endurance exercise, as they work like a chain, where every link may be the weakest part and therefore the limitation.

An increase in the metabolic needs of a muscular territory can be represented by the increase in local $\mathrm{VO}_{2}$. This increase can be obtained by an elevation of alveolar ventilation $\dot{V}_{\mathrm{A}}$ together with a rise in cardiac output ( $\dot{Q})$ and an increase in the extraction of oxygen from the blood which expands the arterial-venous oxygen content difference ( $\mathrm{Dif}_{\mathrm{a}-\mathrm{v}} \mathrm{O}_{2}$ ). The magnitude of these changes will be directly dependent on the intensity of performance during the endurance exercise.

To make it simple the increases in $\mathrm{Q}_{1} \dot{\mathrm{V}}_{\mathrm{A}^{\prime}}$ Dif $\mathrm{O}_{\mathrm{a}-\mathrm{v}} \mathrm{O}_{2}$ necessary to obtain a stable $\dot{V}_{2}$ such as the one shown in Figure 2, may fit in a linear relationship according to the aerobic fitness status and the aim of the exercise.

10) $Q$ increases linearly, according to Ekelund and Holgrem ${ }^{15}$

$$
\left.\mathrm{Q}=\mathrm{Q} \cdot\left(\left[\mathrm{O}_{2}\right]_{\text {venous }} /\left[\mathrm{O}_{2}\right]_{\text {arterial }}\right)+\left(1 /\left[\mathrm{O}_{2}\right]_{\text {arterial }}\right) \cdot \dot{\mathrm{V}} \mathrm{O}_{2} \text { (equation } 3\right)
$$

The slope of the relationship corresponds to $1 /\left[\mathrm{O}_{2}\right]_{\text {arterial' }}$

At the same time $\mathrm{Q} \cdot\left(\left[\mathrm{O}_{2}\right]_{\text {venous }} /\left[\mathrm{O}_{2}\right]_{\text {arterial }}\right)$. This way to express cardiac output shows the physiological importance of the cardiac pump function during endurance exercise. We can see how low aerobic fitness will show a steeper slope in the $\dot{\mathrm{V}}_{2} / \mathrm{Q}$ relationship than that of an elite trained endurance performer.

$2^{\circ}$ ) Increases in Dif $\mathrm{O}_{2}$ shows a Hyperbolic function again according to the previous authors ${ }^{16}$.

$$
\text { Dif } a-\mathrm{vO}_{2}=1 /\left(a+b / \dot{V} \mathrm{O}_{2}\right) \text { (equation 4) }
$$

Therefore the horizontal branch $\left(\mathrm{a}=1 /\left[\mathrm{O}_{2}\right]_{\text {arterial }}\right)$ is asymptotic to the arterial content of oxygen when $\dot{\mathrm{V}}_{2}$ tends towards infinity. This hyperbolic relationship between dif a- $\mathrm{V}_{2} \mathrm{NO}_{2}$ has significance for endurance testing and competition. The maximum arterial-venous oxygen

Figure 3. Organs and living tissues are determinants of $\dot{\mathrm{V}}_{2}$. In black the respiratory system is a $\dot{\mathrm{V}} \mathrm{O}_{2}$ determinant as it allows the entrance of a given amount of oxygen. In red the heart is the organ responsible for pumping the blood containing the oxygen to make it available everywhere in the body. In green the local factors (mitochondria, vessels and blood cells) are responsible for the arterial-venous oxygen content difference.

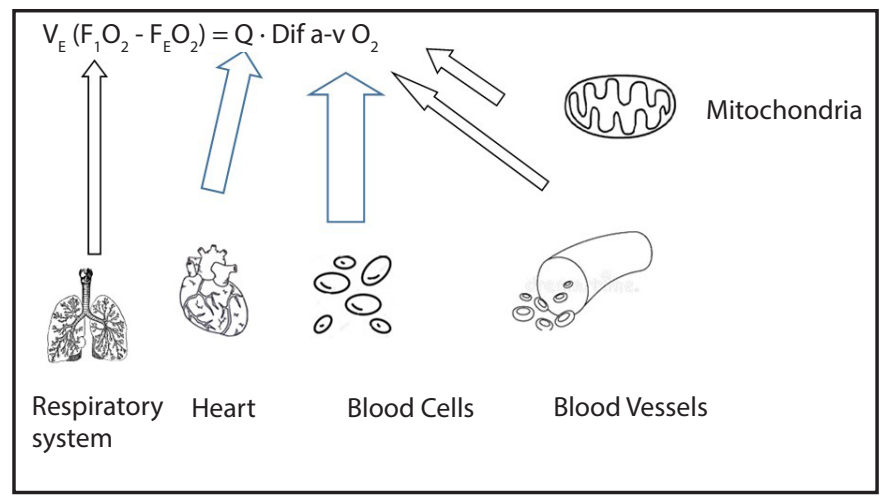


difference value is never reached, because it must necessarily be lower than the arterial blood oxygen concentration. Moreover, taking into account the effects of temperature, $\mathrm{CO}_{2}$ concentration at the muscular level and oxygen concentration on the hemoglobin dissociation curve, minimum oxygen pressure cannot be reached during a maximum test (approximately $20 \mathrm{~mm} \mathrm{Hg}$ ), because it would mean exceeding or surpassing capillary pressure at which the capillaries would collapse.

\section{The increase in ventilation also presents a lineal correlation during a wide range of intensities}

It is well known that the correlation between ventilation and intensity of effort shows two breakpoints ${ }^{16}$. These two points have received several names and we will refer to them as Ventilatory Threshold 1 and 2 $\left(\mathrm{VT}_{1}, \mathrm{VT}_{2}\right)^{17}$. There is still discussion concerning the amount of ventilation necessary to maintain a stable amount of lactate during a long-lasting endurance exercise, both in concept $\mathrm{t}^{18}$ and concerning the methods ${ }^{19}$.

In summary, the representative parameters of cardiovascular, respiratory, erythrocytary, and mitochondrial functions indicated in Figure 3, all adjust in order to maintain Total $\dot{\mathrm{V}}_{2}$ stable during endurance exercise. In fact, the erythrocytary role during the adjustment of cardiovascular function, is basically to increase the capacity of the hemoglobin to liberate oxygen (Bohr effect), transport carbon dioxide (Haldane effect) ${ }^{20}$, and both combined ${ }^{21}$. Furthermore, the mitochondrial function adjustment is critical to increase the diffusion of oxygen into the muscle, possibly becoming a limitation for the extension of endurance exercise at high intensities ${ }^{22}$.

\section{Use of metabolic substrates during endurance exercise}

Table 1 shows the use of energy resources during an exercise at an intensity to elicit $50 \%$ of $\dot{\mathrm{V}}_{2 \max }$ lasting four hours ${ }^{23-25}$.

A simple analysis of Table 1 suggests:

- As effort continues, the relative amount of lipids increases while the relative amount of carbohydrates decreases as is well known. There is discussion about the processes involved ${ }^{23-25}$, but it is generally accepted that lipoprotein lipase in the muscle fiber has a low activity. Therefore, the use of lipid acids depends on the contribution from the liver and the adipose tissue, both subject to high metabolic activity in order to supply fuel to the muscle tissue.

- After the first hour, the supply of glucose from the liver remains constant at an average of $1.8 \mathrm{mmol} / \mathrm{L}( \pm 0.2)$.

- The connection between both types of tissues and the liver will prevent the possibility of reaching a point where an athlete could

Table 1. Substrate use during 4 hours of constant load exercise.

\begin{tabular}{lccccc}
\hline Substrate & Rest & $\mathbf{1 ~ h}$ & $\mathbf{2 ~ h}$ & $\mathbf{3} \mathbf{h}$ & $\mathbf{4} \mathbf{~ h}$ \\
\hline Carbohydrates (\%) & 54 & 27 & 20 & 17 & 13 \\
Lipids (\%) & 46 & 73 & 80 & 83 & 87 \\
Carbohydrates (mm/min) & 7.2 & 3.6 & 2.6 & 2.3 & 1.7 \\
Lipids (mm/L) & 0.45 & 0.71 & 0.78 & 0.81 & 0.87 \\
Glycemia (mmol/L) & 4 & 2 & 1.5 & 1.8 & 2 \\
\hline
\end{tabular}

find the muscle empty of fuel during exercise (discussed further in "regulation and control during endurance exercise").

Taking into account the total availability of glucose in the liver (around $90 \mathrm{~g}$ of glycogen), an athlete running a marathon could sustain his or her running intensity for around $20 \mathrm{~min}$ if it depended solely on glucose (consuming around $5 \mathrm{~g} / \mathrm{min})^{26}$. Besides, there is a gradual decrease in muscular glycogen although there is a need to use it in order to maintain mechanical performance ${ }^{26}$. According to this, the coordination between muscle, liver and adipose tissue is essential.

The role of the Liver. The liver, via complex mechanisms of internal regulation (through enzymes) together with external regulation (through hormones), maintains glycemia during endurance exercise as can be seen in Table 1. Once the availability of glycogen in the liver is finished some other tissues can contribute to glycemia providing substrates (amino acids, glycerol or lactate) in order to maintain the availability of glucose ${ }^{27,28}$. But this is a slow process. In fact, as athletes will be ingesting glucose, it will cause an increase in the alanine and Cori cycles which would be hard to detect during long duration endurance exercise. An increase in the Cori cycle during recovery, even in fasting conditions has appeared in the literature ${ }^{29}$. Although the main destination for glucose will be the nervous system, as it is significantly dependent on it, during endurance exercise there is a high consumption of this substrate in muscle too.

The process of the interaction between glucose and fatty acids ${ }^{30}$ allows the use of the latter in certain situations to save glucose, being therefore of importance during endurance exercise $\mathrm{e}^{30-32}$. The increase in the concentration of fatty acids in the blood together with an increase in their absorption by the muscle fibers causes an increase in oxidation while at the same time producing a decrease in the oxidation of glucose. This adjustment is achieved thanks to the control of key enzymes; for example, a change in the activity of glycogen-phosphorylase compared to glycogen-synthase. Control of the former is complex but there are at least three known mechanisms involved in the change from the inactive to the active form of the enzyme ${ }^{24}$. The most powerful of these mechanisms is the action of hormones that activate the protein kinase and, in turn, the enzyme ${ }^{33}$. At the same time there is an increase in the muscular destruction of glycogen and there is also an increase in the release of fatty acids by adipose tissue due to the activation of the triacylglycerol lipase and the deactivation of the lipoprotein lipase ${ }^{34}$. Again, these changes are caused by the action of hormones through their effect on the protein kinase ${ }^{24}$. Clearly, the coordination of the process of interaction between glucose and lipids is indispensable for endurance exercise, in order to allow the simultaneous consumption of both fatty acids and carbohydrates ${ }^{35}$.

Hormonal control. As has been previously noted, the liver is a target organ for most hormones during exercise. We traditionally divide these hormones into anabolic and catabolic ${ }^{31}$ and according to this basic division it has been suggested that the relative concentration of anabolic hormones should decrease while the relative concentration of catabolic hormones should increase during exercise. During long duration endurance exercise, somehow the hypothesis fails to prove true in the analysis of the concentration of hormones in the blood. For example, the growth hormone increases during long duration endurance exercise ${ }^{36}$. Since this hormone is clearly anabolic, the possible 
explanations for this "paradoxical response" have been based on the stress caused by exercise increasing the concentration of $\mathrm{GH}-\mathrm{RH}$ while decreasing somatostatin (SS), respectively activator and inhibitor of GH liberation. The two hypothalamic neurohormones are subject to modulation by a host of neurotransmitters, especially the noradrenergic and cholinergic ones and other hypothalamic neuropeptides, and are the final mediators of metabolic, endocrine, neural, and immune influences for the secretion of $\mathrm{GH}^{36}$. We may consider the response of $\mathrm{GH}$ liberation coherent with both acute stress and endurance exercise, in itself an acute stress. But it has to be considered that the lipolytic effect and the increase in plasma glucose caused by GH are both desirable in this type of exercise, while it also eases the entrance of amino acids into the fiber cells and stimulates protein synthesis.

Moreover, the hormones considered regulators of glycemia ${ }^{31}$ have a determinant role during endurance exercise to control the use of carbohydrates. The importance of maintaining glycemia can hardly be exaggerated, since nervous system function strongly relies on it. On the one hand, the increase of glucagon enhances glucose availability for muscle tissue and the nervous system. On the other hand, insulin is an anabolic hormone and so decreases ${ }^{31}$, but only to the point where it still increases the transport of glucose to tissues, as the entrance of glucose to the muscle is not only an effect of muscular contraction during exercise $\mathrm{e}^{37,38}$ but insulin remains fundamental in glucose consumption ${ }^{39}$. Some other glucose regulator hormones (epinephrine and cortisol) may be of importance during endurance exercise ${ }^{31}$.

\section{Thermoregulation in endurance exercise}

Regulation of body temperature is under the control of a complex feedback system. There are receptors, integration centers and active responders ${ }^{40}$. During exercise the transformation of chemical energy from the fuel into heat approximates $70 \%$ and $1 \mathrm{~L}$ of oxygen consumption equals $4.8 \mathrm{Kcal}$. The object of thermoregulation is to control the core temperature in a range where homeostasis is possible, even while we are exercising. There are several mechanisms available to dissipate the excess of heat ${ }^{41}$. Evaporation is the principal measure to dissipate heat, reaching $40 \%$ of energy produced under normal temperature and humidity.

Sweat production and evaporation are related to exercise intensity up to the level at which sweat production reaches its maximum. There is a cost to be paid for this efficient control mechanism ${ }^{41}$ : water and electrolytes loss, both of them determinant ingredients of endurance performance. The amount of water lost in sweat can increase to $4 \mathrm{~L} / \mathrm{h}$ in some subjects, leading to a situation termed dehydration if not corrected. Again, there are important mechanisms previously mentioned, such as substrate metabolic processes and hormones (the reninangiotensin-aldosterone axis, or the antidiuretic hormone relationship to thirst), that will play a determinant role in the attempt to maintain the internal hydro and electrolytic balance.

There is another additional cost to be considered for thermal regulation. During endurance exercise there is also a competition between muscle and skin vascular territories for the cardiac output ${ }^{42,43}$ and a limitation for performance due to blood flow redistributed to the skin.

\section{Integrated physiological response during endurance exercise}

It has been already mentioned in the introduction that the control of physiological responses during endurance exercise belongs to the nervous system. and the involved mechanisms can be basically divided into: feedforward and feedback mechanisms. Feedforward mechanisms are those that are activated previously to any reflex mechanism that can be elicited by the effort. Feedback mechanisms are those that will respond to signals from different receptors. Feedforward mechanisms allow an immediate activation of different processes, although they have a drawback in that they are not being controlled. It is the interaction between these two types of mechanisms that allows precise control of the variables to attain a state of homeostasis during endurance exercise.

As shown in Figure 2, $\dot{\mathrm{V}}_{2}$ stability implies nervous regulation of respiratory and cardiovascular systems while the active tissues must use the increased oxygen supply for energy extraction. Nevertheless, pointing to the specific structures in the nervous system responsible for this regulation is harder. The intervention of descending pathways on the regulation of the cardiorespiratory apparatus has been proposed for over a century. Zunt suggested the term "cortical irradiation" for these locomotor and cardiorespiratory descending pathways but recently they have been grouped under the term Central Command (CC), which is currently accepted. The study of the interaction between CC with the nociceptors and metaboreceptors during exercise is still a challenge for science.

In the next few lines there will be a brief mention of the nervous mechanisms implied in maintaining homeostasis during endurance exercise in an extreme ultra-resistance event ${ }^{3-7}$ considering the main mechanisms signaled previously: feedforward, feedback and the integration of feedforward-feedback.

\section{Feedforward control of endurance exercise}

An important portion of the fast increase in $\dot{\mathrm{V}}_{2}$ at the onset of exercise, shown in Figure 2 is caused by CC activity, roughly a ninefold increase in $\dot{V}_{2}$ (from $213 \mathrm{ml} / \mathrm{min}$ to $1990 \mathrm{ml} / \mathrm{min}$ ) in $1.5 \mathrm{~min}$. To achieve this, the cardiovascular and respiratory functions logically must increase correspondingly (see Figure 3). The feedforward mechanism suggests an increase in $\dot{V}_{2}$ far in excess of demand. That is to say, at the beginning of an exercise of constant intensity more oxygen is offered and consumed through the feedforward mechanism. This excess $\dot{V}_{2}$ is known as the oxygen deficit. The initial increase in $\dot{\mathrm{VO}}_{2}$ requires an increase in cardiac output (Q) and alveolar ventilation ( $\mathrm{V} A)$. The increase in $\mathrm{Q}$ is mainly due to vagal inhibition together with activation of the sympathetic vegetative nervous system ${ }^{44}$.

\section{The feedback mechanism during endurance exercise}

The mean value of $\dot{V}_{2}$ in Figure 2 is $3684 \mathrm{ml} / \mathrm{min}( \pm 83 \mathrm{ml} / \mathrm{min}$ ). To maintain this value, the cardio-respiratory control centers adjust the efferent signal to the cardiovascular and respiratory systems for peripheral feedback. The participation of the different signals for the cardio-respiratory adjustment is complex to assess, as it comes from 
baroreceptors, peripheral and central chemo-receptors, mechanoreceptors of the respiratory musculature and the pulmonary parenchyma. All this information reaches the medulla, the fundamental center of cardio-respiratory control, where the respiratory nuclei (dorsal and ventral) and cardiovascular nuclei (nucleus of the solitary tract, dorsal nucleus of the vagus and vascular center) are located. The result is:

- An adjustment of the "central" parameters (cardiac output and alveolar ventilation) to maintain a ventilation/perfusion ratio (VA/Q) close to the unit, which facilitates the exchange of gases.

- An adjustment of the "peripheral" parameters: redistribution of blood flow, increasing in the active territories (muscular, cerebral and coronary), decreasing in the less active ones (digestive and renal). Brain flow is basically maintained by self-regulating mechanisms, mainly by the effect of carbon dioxide. Brain circulation is very sensitive to variations in the partial pressure of carbon dioxide, so that its increase (hypercapnia) causes vasodilatation and decrease (hypocapnia) the opposite effects. Coronary blood flow during exercise is mainly maintained by self-regulating mechanisms, mediated by molecules released as a result of myocardial metabolic controls and by the action of the vegetative nervous system. The importance of the activity of the myocardial metabolism is evidenced by the arteriovenous difference, which increases slightly during exercise.

- An adjustment of the receivers for movement control in relation to cardio-respiratory variations. For example, the sensitive terminations III and IV of the muscles are sensitive to metabolic conditions ${ }^{45}$. Control of muscle blood flow is mediated by the release of lactic acid, $\mathrm{CO}_{2}$ partial pressure, concentration of $\mathrm{H}^{+}$and other molecules (bradykinin and prostaglandins). These variables trigger reflex reactions (known as chemoreflex or metaboloreflex), mediated by the sympathetic nervous system that adjust cardiac output and systemic blood pressure to maintain the metabolic conditions in the muscle territory. However, the mechanisms of cardio-respiratory regulation may be misadjusted when central temperature control is a priority, especially in hot and humid environments. The cutaneous vasoconstriction produced during exercise comes into conflict with the greater demand for blood flow in the skin that is necessary to promote sweating. This discrepancy between heat dissipation and cardio-respiratory control can affect ventricular performance. This contrast explains in part the phenomena known as cardiovascular drift and respiratory drift.

- Finally, it is important to remember that metabolism is also under peripheral feedback control too. Previous points have mentioned that different metabolic pathways do have intrinsic regulation mechanisms, but the activation of the sympathetic nervous system increases the response of said mechanisms (the transformation of glycogen-phosphorylase from inactive to active will be increased as an example).

\section{Integration of feedforward and feedback mechanisms during endurance exercise}

Figure 1 represents in a diagram both previously presented physiological regulation mechanisms interacting during an endurance exercise.
Solid lines represent feedforward mechanisms while the dotted lines represent feedback mechanism. Representing a continuous situation where the feedforward mechanism is acting as a launching team and "starts the engine" while progressively receiving the addition of the "maintenance team" represented here by the feedback mechanism.

Sequential activation of motor units is produced following Henneman's size principle ${ }^{46}$. Therefore, the motoneurons are activated due to neuron cell size and distribution of the cells in the anterior horn of the spinal $\operatorname{cord}^{47}$. According to this principle the motoneurons would be recruited always in the following order of motor units: Slow Twitch $(\mathrm{ST}) \rightarrow$ Fast Slow twitch $\rightarrow$ Fast Twitch (FT). An increase in respiratory and cardiovascular activity can be perceived by the increase in cardiac output (Q) and alveolar ventilation (VA) allowing an adequate distribution of oxygen to the active tissues during effort.

As a result of the increased needs produced by the effort simultaneous to the increased availability of oxygen, the muscles increase absorption and consume the necessary amount of oxygen to perform the mechanical work demanded while also being capable of sustaining a certain intensity during an extended period of time. In order to maintain oxygen consumption (VO) the nervous system exerts control over hormones capable in turn of either speeding up or slowing down the internal control mechanisms of each metabolic pathway.

According to this distribution of tasks, the feedback mechanisms represent the activity of centers located hierarchically below the encephalic level while the feedforward mechanism is located in higher encephalic structures. There is however a significant amount of interaction between both mechanisms. Thus, the CC acts on physiological functions, such as cardiac output, the regulation of which is preferentially but not exclusively in the spinal bulb. Peripheral feedback also provides information on the situation of the body as a whole. The importance of central command and peripheral feedback in controlling physiological variables during endurance exercise is yet to be determined. The discussion lies in knowing:

- What nervous structures manage somatic-neurovegetative coordination?

- Is there a single central command or are there different central commands? The question is whether there is a CC to control movement and another for cardiovascular or cardiorespiratory control, all capable of distinct independent functioning, while being perfectly matched and coordinated during exercise?

- Is recruitment completely explained simply by the electrophysiological profile of motor units or is the activity of descendent pathways on the anterior horn of the medulla capable of selecting a different order? ${ }^{11}$.

- In turn, are descendent pathways the origin of other collateral descendent pathways this time directed to the cardiorespiratory control centers, deeming therefore unnecessary the existence of a specific CC for cardiorespiratory regulation?

Even if the doubts already expressed have to be all taken into account, in the end the nervous system exerts a perfect regulation over motor control, as well as over all the functions involved in movement. The rest of control mechanisms (feedforward and feedback) are essentially meant to accomplish and maintain the state of the different physiological variables during an endurance exercise, in such a way as to be capable 
of performing at high intensities for a long period. Obviously, these mechanisms behave in a significantly different manner according to the different intensities achieved and depending on the purpose of the effort. Usually when the aim of the exercise being executed is to improve or maintain the health status, the activation of both mechanisms will only be minimal, i.e. a routine of $6 \mathrm{~km}$ of footing per day, especially if we compare it with the maximal activation found in someone training to improve running performance with the intention of running a complete marathon race at $3 \mathrm{~min} / \mathrm{km}$. In both cases, the difference for the nervous system will only be one of targets and therefore it will adjust to the separate situations perfectly, showing that endurance exercise is a unique physiological integration paradigm.

\section{Conflict of interest}

The authors do not declare a conflict of interest.

\section{Bibliography}

1. Mitchell JH, Haskell W, Snell P, Van Camp SP. Task Force 8: classification of sports. J Am Coll Cardiol. 2005;45:1364-7.

2. Grainer A, Zerbini L, Reggiani C, Marcolin G, Steele J, Pavei G, et al. Physiological and perceptual responses to nordic walking in a natural mountain environment. Int J Environ Res Public Health. 2017;14:1235

3. Black KE, Skidmore PM, Brown RC. Energy intakes of ultraendurance cyclists during competition, an observational study. Int J Sport Nutr Exerc Metab. 2012;22:19-23.

4. Clemente-Suarez VJ. Psychophysiological response and energy balance during a 14-h ultraendurance mountain running event. Appl Physio/ Nutr Metab. 2015;40:269-73.

5. Kunces $\sqcup$, Johnson EC, Munoz CX, Hydren JR, Huggins RA, Judelson DA, et al. Observed dietary practices of recreational ultraendurance cyclists in the heat. J Strength Cond Res. 2016:30:1607-12.

6. Armstrong LE, Johnson EC, Kunces LJ, Ganio MS, Judelson DA, Kupchak BR, et al. Drinking to thirst versus drinking ad libitum during road cycling. J Ath/ Train. 2014;49:624-31.

7. Armstrong LE, Johnson EC, McKenzie AL, Ellis LA, Williamson KH. Ultraendurance cycling in a hot environment: thirst, fluid consumption, and water balance. J Strength Cond Res. 2015;29:869-76.

8. Granger DN, Holm L, Kvietys P. The gastrointestinal circulation: Physiology and pathophysiology. Compr Physiol. 2015;5:1541-83.

9. Verbalis JG. Renal function and vasopressin during marathon running. Sports Med. 2007;37:455-8.

10. Mueller PJ, O'Hagan KP, Skogg KA, Buckwalter JB, Clifford PS. Renal hemodynamic responses to dynamic exercise in rabbits. J Appl Physiol. 1998;85:1605-14.

11. Lemon RN. Descending pathways in motor control. Annu Rev Neurosci. 2008:31:195-218.

12. Christensen NJ, Galbo H. Sympathetic nervous activity during exercise. Annu Rev Physiol. 1983;45:139-53.

13. O'Leary DS, Rossi NF, Churchill PC. Substantial cardiac parasympathetic activity exists during heavy dynamic exercise in dogs. Am J Physiol. 1997;273:2135-40.

14. Geppert J, Zuntz N. Ueber die regulation der athmung. Archiv für die gesamte Physiologie des Menschen und der Tiere. 1888;42:189-245

15. Ekelund LG. Circulatory and respiratory adaptation during prolonged exercise. Acta Physiol Scand Suppl. 1967;292:1-38.

16. Wasserman K, Hansen J, Sue DY, Stringer W, Whipp BJ. Principles of exercise testing and interpretation: pathophysiology and clinical applications. Philadelphia: Lippincott: Williams and Wilkins; 2004. p. 180

17. López-Chicharro J, Legido JC, Terrados N. Umbral anaeróbico, bases fisiológicas y aplicación. Phyladelphia: Lippincott Williams and Wilkins; 1991.p.114

18. Billat VL, Sirvent P, Py G, Koralsztein JP, Mercier J. The concept of maximal lactate steady state: a bridge between biochemistry, physiology and sport science. Sports Med. 2003;33:407-26.

19. Beneke R. Methodological aspects of maximal lactate steady state-implications for performance testing. Eur J Appl Physiol. 2003;89:95-9.
20. Grant BJ. Influence of Bohr-Haldane effect on steady-state gas exchange. J Appl Physiol Respir Environ Exerc Physiol. 1982;52:1330-7.

21. Belardinelli R, Barstow TJ, Porszasz J, Wasserman K. Skeletal muscle oxygenation during constant work rate exercise. Med Sci Sports Exerc. 1995;27:512-9.

22. Poole DC, Richardson RS. Determinants of oxygen uptake. Implications for exercise testing. Sports Med. 1997;24:308-20.

23. Hamilton MT, Hamilton DG, Zderic TW. Exercise physiology versus inactivity physiology: an essential concept for understanding lipoprotein lipase regulation. Exerc Sport Sci Rev. 2004;32:161-6.

24. Oscai LB, Essig DA, Palmer WK. Lipase regulation of muscle triglyceride hydrolysis. J Appl Physiol. 1990;69:1571-7.

25. van Hall G. The Physiological regulation of skeletal muscle fatty acid supply and oxidation during moderate-intensity exercise. Sports Med. 2015;45:S23-32.

26. Suh SH, Paik IY, Jacobs K. Regulation of blood glucose homeostasis during prolonged exercise. Mol Cells. 2007;23:272-9.

27. Rodgers CD, Vranic M. Mediation of glucoregulation at rest and during exercise by the glucose-fatty acid cycle: in vivo and in vitro studies. Can J Appl Physiol. 1998;23:534-57.

28. Winder WW. Regulation of hepatic glucose production during exercise. Exerc Sport Sci Rev. 1985;13:1-31.

29. Fournier PA, FairchildTJ, Ferreira LD, Brau L. Post-exercise muscle glycogen repletion in the extreme: effect of food absence and active recovery. J Sports SciMed. 2004;3:139-46.

30. Rodgers CD. Fuel metabolism during exercise: the role of the glucose-fatty acid cycle in mediating carbohydrate and fat metabolism. Can J Appl Physiol. 1998;23:528-33.

31. Powers S. Exercise physiology: Theory and application to fitness and performance. New York: McGraw-Hill Higher Education; 2014.p.573.

32. Spriet LL. Regulation of fat/carbohydrate interaction in human skeletal muscle during exercise. Adv Exp Med Biol. 1998;441:249-61

33. Manabe Y, Gollisch KS, Holton L, Kim YB, Brandauer J, Fujii NL, et al. Exercise traininginduced adaptations associated with increases in skeletal muscle glycogen content. FEBS J. 2013;280:916-26

34. Oscai LB. Exercise and lipid metabolism. Prog Clin Biol Res.1981;67:383-90

35. Spriet LL. New insights into the interaction of carbohydrate and fat metabolism during exercise. Sports Med. 2014;44:S87-96

36. Muller EE, Locatelli V, Cocchi D. Neuroendocrine control of growth hormone secretion. Physiol Rev. 1999;79:511-607.

37. Ihlemann J, Ploug T, Hellsten Y, Galbo H. Effect of tension on contraction-induced glucose transport in rat skeletal muscle. Am J Physiol. 1999;277:E208-14.

38. Wright DC, Hucker KA, Holloszy JO, Han DH. Ca2+ and AMPK both mediate stimulation of glucose transport by muscle contractions. Diabetes. 2004;53:330-5.

39. Constable SH, Favier RJ, Cartee GD, Young DA, Holloszy JO. Muscle glucose transport: interactions of in vitro contractions, insulin, and exercise. J App/ Physiol. 1988;64:2329-32.

40. Tansey EA, Johnson CD. Recent advances in thermoregulation. Adv Physiol Educ 2015;39:139-48

41. Gagge AP, Gonzalez RR. Mechanisms of Heat Exchange: Biophysics and Physiology. En: Terjung R. Handbook of Physiology, Environmental Physiology. Comprehensive Physiology. Hoboken, New Jersey: Wiley Online Library; 2011. p. 45-84.

42. Gonzalez-Alonso J. Human thermoregulation and the cardiovascular system. Exp Physiol. 2012;97:340-6.

43. Lim CL, Byrne C, Lee JK. Human thermoregulation and measurement of body temperature in exercise and clinical settings. Ann Academy Med Sing. 2008;37:347-53.

44. Tony G, Waldrop FA, Iwamoto A. H. MJ. Central neural control of respiration and circulation during exercise. En: Laughlin MH, Korthuis RJ, Duncker DJ, Bache RJ. Handbook of Physiology Exercise: Regulation and Integration of Multiple System. Oxford: Oxford University Press; 1996. p. 705-69.

45. Rowell LB, O'Leary DS, Kellogg JDL. Integration of cardiovascular control systems in dynamic exercise. En: Laughlin MH, Korthuis RJ, Duncker DJ, Bache RJ. Handbook of Physiology Regulation and Integration of Multiple Systems. Oxford: Oxford University Press; 1996.

46. Henneman E. Relation between size of neurons and their susceptibility to discharge Science. 1957;126:1345-7.

47. Duchateau J, Enoka RM. Human motor unit recordings: origins and insight into the integrated motor system. Brain Res. 2011;1409:42-61. 